\title{
Theories of Motivation and Their Application in Organizations: A Risk Analysis
}

\author{
Reuben M. Badubi
}

\author{
School of Management, Wuhan University of Technology, Wuhan, P.R. China
}

\begin{abstract}
The aim of this paper is to compare and contrast the theories of motivation and how they are used to inspire employees to develop the drive to achieve. The importance of motivation in organizations and job satisfaction is vital for the achievement of organizational goals and objectives. The consequences of organizations operating without any purpose of motivation towards its employees are far catastrophic, such as depression, turnover, burnout which can derail the success of organizations. For organizations to make employees their biggest asset and retention purposes, motivation should be a priority. The study tries to help organizations with suggestions to cultivate conducive atmospheres and relationships for employees to work under, to foster positive attitudes towards their work. A qualitative approach and theory based application were considered for this study.
\end{abstract}

Keywords: Motivation, Job Satisfaction, Intrinsic, Extrinsic

\section{Introduction}

In all enterprises whether private or state owned, motivation plays a key role in driving employees towards achieving their goals, organizational goals and to a certain extent the dreams of their nations. There are many theories of motivation, and they mostly give a relation or influence the outcomes of employee job satisfaction. There are three main theory categories, namely content theories, process theories and contemporary theories (Saif, Nawaz, Jan \& Khan, 2012). Generally speaking, these theories include Maslow's hierarchy of needs, Herzberg's motivator-hygiene (or two-factor) theory, Alderfer's Existence, Relatedness and Growth theory, and McClelland's needs theory. How motivation comes about and how it leads to satisfaction is explained by process theories; theories that fall into this category include Porter-Lawler's model and expectancy theory by Vroom. Contemporary theories of motivation incorporate equity, control and agency theory, as well as goal setting, reinforcement, and job design theory. The theories of motivation maybe categorized according to their definitions and purpose but critical analysis reveal that they are all linked, they lead to serving satisfaction in employees. The use of both content and process theories must be put into practice to motivate employees effectively. In extrinsic motivation, the factors (hygiene's) that satisfy lower-level needs are different from those (motivators) that satisfy or partially satisfy higher-level needs. If hygiene factors (factors outside the job itself, such as working conditions, salary and incentive pay) are inadequate, employees become dissatisfied. Instead of relying on hygiene's, the manager interested in creating a self-motivated workforce should emphasize job content or motivation factors. Managers do this by enriching worker's jobs so that the jobs are more challenging and by providing feedback and recognition (Dessler, Barkhuizen, Bezuidenhout, Braine and Plessis, 2011 , p433). Rewards as the main factor of motivation can also encourage retention within the organization, and the broader employment relationship and social exchange are significant. Motivation's whole idea is to provide employees with sureties of job security, 
Reuben M. Badubi

Theories of Motivation and Their Application in Organizations: A Risk Analysis

nice working condition, loyalty and belonging to the enterprise, as well as the workforce given some challenges.

\section{Motivation}

Locke (as cited by Saari and Judge, 2004, p396) defined motivation as "a pleasurable or positive emotional state resulting from the appraisal of one's job experiences". This definition draws attention to two aspects, in particular, namely the emotional attachment an employee has to their job, and the deliberate review of an employee's work by the employer. According to David and Anderzej (2010), motivation can be understood as cognitive decision making in which the intension is to make the behavior that is aimed at achieving a certain goal through initiation and monitoring. At work places, reviews are done using appraisals and appraisals at work have predetermined standards, and their outcome may provoke an emotional reaction in the employee, and this reaction will determine how satisfied or dissatisfied an employee is. Good marks in reviews may reflect that an employee is satisfied and bad marks may reflect the opposite. In every employee, motivation maybe because outside factors (extrinsic) such as rewards or within an individual (intrinsic), desire to do better.

\subsection{Job Satisfaction}

For us to help understand underpinnings to motivation, we must first explore what job satisfaction means because motivated employees will have a job satisfaction. According to Kumar and Singh (2011, p.12), job satisfaction (or the lack thereof) depended on the employee's perception of the degree to which his work delivers those things that he desires - how well outcomes are met or expectations perhaps even exceeded. Regardless of the actual circumstances and situation, job satisfaction is an emotional response that cannot be seen, only inferred. Jehanzeb, Rasheed, Rasheed and Aamir (2012, p.274) held a similar view, defined job satisfaction as "a sensation employees have about their work environment and their expectations toward work". Depending on the rewards and incentives employees receive and management's motives for giving them, employees will respond to their work environment by being productive. Organisations must be seen to support employees in their daily work in order to bring about loyalty and improve retention by removing elements that may create dissatisfaction, while bearing in mind that in a heterogeneous environment, with male and female employees from different age groups, generations, and (to a certain extent) backgrounds, and with varying qualifications or experience, no single element will produce either universal approbation or collective disapproval.

\section{Theories of Motivation}

\subsection{Maslow's Hierarchy of Needs}

According to Smith \& Cronje (1992), the way Maslow's theory is explained relies on the fact that people want to increase what they want to achieve in life and their needs are prioritized according to their importance. Deriving from the hierarchy of needs by Maslow, content theories of job satisfaction revolve around employees' needs and the factors that bring them a reasonable degree of satisfaction (Saif et al., 2012). Based on the basic physical, biological, social and psychological needs of human beings, Maslow came up with a five-stage theory that places the needs of the individual in different categories and prioritizes their attainment. These categories, in order of decreasing priority, are:

- physiological needs (food, shelter, clothing);

- safety and security needs (physical protection);

- social needs (association with others);

- esteem needs (receiving acknowledgement from others); and

- self-actualisation needs (the desire for accomplishment or to leave behind a legacy). 
Maslow's hierarchy of needs forms the basis of theories that try to explain job satisfaction. Teachers, like all people, have needs that have to be satisfied. Besides the basic needs for food, shelter and clothing, safety from physical, harm, and social interaction, they also need the recognition and appreciation of students, colleagues, and parents.

\subsection{Herzberg's Two-Factor Theory/Motivator-Hygiene}

Herzberg's Two-factor theory, also known as Motivator-Hygiene, emanated from a study conducted among accounts and engineers to determine what makes an individual feel good or bad about their job (Saif et al., 2012). Regarding 'satisfiers', Herzberg noted that there were five features of work that bring about satisfaction, namely achievement, recognition, the job itself, responsibility and advancement. At the other end of the spectrum, Herzberg identified institutional politics, the management approach, supervision, pay, relationships at work and working conditions as factors that may demoralize employees. Golshan, Kaswuri, Agashahi and Ismail (2011:12) assert that organizations are increasingly applying Herzberg's theory to create opportunities for "personal growth, enrichment and recognition" among their employees. Employees should be promoted after completing certain stages of their career and should receive recognition for special achievements - for example, when they produce exceptional results in their subject areas; on a more basic level, they should also be given responsibility to determine how to handle tasks that relate to their jobs. The Two-factor theory has however drawn its share of criticism. Golshan et al. (2011) point out that it fails to distinguish between physical and psychological aspects and to precisely explain what motivators are and how they differ from hygiene factors; it also fails to express the degrees of satisfaction and dissatisfaction as a measure instead of using numbers. Another criticism leveled against it is that it makes assumptions that every individual will react in the same way in the similar situation.

\subsection{McGregor's $X$ and $Y$ Theories}

McGregor's (1960) Theory $X$ and $Y$ models categorize employees as belonging to one of two groups based on two sets of assumptions. Theory $X$ assumptions take a negative perspective of people: People can have "an inherent dislike for work and avoid it if possible; because of this, they must be coerced, controlled, directed and threatened with punishment to make them work. They prefer to be directed, avoid responsibility, have little ambition, and want security" (Saif et al. 2012, p.138). Theory $Y$ assumptions take the opposite view: the mental and physical inputs expended at the workplace are equated and par with those rest or play. External factors or any threats from outside may not be the sole influence for exerting effort. Workers or people can exercise caution and discipline to have objectives achieved, but the hunger in their desire to commit to objectives is dependent on how big are the rewards as assigned to that kind of achievement. Under normal circumstances, people can adapt to seek responsibility and not only accept it (Saif et al., 2012, p.1357). Applying these assumptions to a school environment, one could argue that two of the main causes of dissatisfaction among teachers are having to deal with problem students and a strict and inconsiderate management, for example a principal who is coercive and does not appreciate the efforts of teachers, or an overly directive principal who never delegates or allows teachers to make independent decisions. Conversely, a supportive principal may be a source of job satisfaction to teachers (Alavi \& Askaripur, 2003, p.312).

\subsection{McClelland's Need Achievement Theory}

McClelland's need achievement theory postulates that some people are driven to success through seeking "personal achievement rather than rewards themselves" (Saif et al., 2012, p.1387). This theory is readily applicable to academic environments and explains why some teachers are high achievers, despite the difficulties they face: they set themselves high goals and achieving these goals is what drives them. Alderfer's ERG theory is related to Maslow's hierarchy of needs but reduces Maslow's five categories of a need to three; 


\section{Reuben M. Badubi}

Theories of Motivation and Their Application in Organizations: A Risk Analysis

namely, relatedness being (esteem/social needs), then growth being (self-actualization) and existence which is (security/physiological needs).

\subsection{The equity theory}

Process theories explain 'how' satisfaction comes about, as opposed to 'what' causes motivation. The equity theory postulates that employees will weigh their input into a job against the output they receive from it - the more the rewards, the greater their satisfaction. This resonates with Naveed et al. (2011, p.302) definition of job satisfaction as the difference between employee input and job output. Regarding this theory, employees who perceive that they receive more output from their jobs than what they put into them will experience job satisfaction. Certain aspects of the job itself also shape how an employee perceives it. Tasks that are clarified bring a better job satisfaction since a clear role breeds a work force that is happy, committed and shows much involvement in work that is done. Authors identified five major job characteristics that impact on the psychological state of an employee and influence their motivation and job satisfaction, as well as their levels of absenteeism, namely the variety of skills involved in a task, the identity and significance of the task, autonomy, and feedback. Employees compare their input-outcome ratio with that of other employees and if they perceive it to be fair, employees will experience satisfaction (Robbins, 2007). If employees perceive an inequity in their input-outcome ratio compared to other employees, they become dissatisfied and less motivated.

\subsection{Value - Percept Theory}

Individual's values determine their satisfaction on their job because employees in organizations hold different value systems, therefore based on this theory, their satisfaction levels will also differ. Having a look at Value - Percept theory, the assumption is that the difference between expectations and what is received can bring dissatisfaction depending on how important the job is to the individual (Anderson, Ones, Sinangil \& Viswesvaran, 2001, p.32). The potential problem with this theory is that there is a possibility of a relationship between what people desire and what they consider important. These concepts can be separable theoretically but practically hard to differentiate.

\subsection{Vroom's Expectancy Theory}

Vrooms's expectancy theory stipulates that behavior is a product of choices that are available for to be prioritized. The idea is to derive satisfaction and minimize dissatisfaction in employees. Individual factors such as personality and skills determine performance (Wagner and Hollenburg, 2007). This theory also explains that performance, motivation, and effort are within an individual's motivation and variables such as valence, instrumentality, and expectancy verifies this. The higher the effort in work relates to the higher the performance.

\subsection{Porter-Lawler Model}

This is a comprehensive and more complete theory of motivation which is inclusive of diverse aspects. This model can give details of the fiber relation that exists between job performance and attitudes which perfectly defines managers. The model also touches on the assumptions of human behavior. The deductions of the model assume that individual behavior is influenced by both internal and external factors, rational and make own choices about their behavior, have different goals, desires and needs. Finally, individuals decide between alternative behaviors (Wagner and Hollenburg, 2007). 


\section{Risk Analysis of De-Motivated Employees in Organizations}

Employees who lack motivation in the work places are a risk factor when it comes to executing day to day operations of the business. Some employees are engaged in company equipment and tools on a daily basis, some of which need maximum attention and safety when using. So it is the responsibility of the organization to have a well-balanced workforce of employees and their emotions as far as work issues are concerned.

\subsection{Operational Risks}

- Absenteeism: Van der Merwe and Miller $(1988$, ) cite a definition used by the United States Department of Labour which defines absenteeism as the failure of workers to report on the job when they are scheduled to work. Regarding this definition, non-attendance such as vacation leave, military service, block release leave and suspension do not qualify as absenteeism and should be completely excluded from the ensuing absenteeism analysis process. Levy (2006, p.412) provides a more comprehensive definition in describing absenteeism as the chronic or continued failure of the employees to attend for duty, especially when the pattern of absenteeism suggests that either the absence is avoidable, or that the employees failed in their duty to the employer in accordance with their contract of employment or common law duty to attend the place of work regularly and reliably.

- Poor quality work: In terms of quality outputs and results, disgruntled employees will not perform at their best hence produce shoddy products or services that will not be competitive in the market thereby costing an organization.

- Toxic Work environment: Cordial and mutual relationship among employees will be disrupted. Employee's behaviour and attitudes will be affected since their moral is down.

\subsection{Personnel Risks}

It is the desire of organization to keep their staff for longer periods of time. Organisations spend a lot of money and time in training their employees. High staff turnover due to unhappy employees will cost the organization of all the spent resources. This will result in disruptions of organization's operations as replacement of staff will be needed as well as more costs of another training for new employees. Strategic leadership is the critical point in achieving companies objectives. The negative side of leaders can jeopardize the firm's operations (Hogan and Hogan 2001).

\subsection{Reputational Risks}

Dissatisfaction: The morale of the entire office can be brought down when one employee lacks motivation. Employees who are not satisfied with their job might resort to quitting; therefore, this scenario should be avoided. The employees are to perform to their abilities in order to satisfy their customers and to retain them all the time. It is very easy for customers to spread word of mouth about a company that they are not satisfied with its performance, and the information can be spread very rapidly which can ruin the company's reputation. Leadership is very vital because according to Stankiewicz-Mroz (2015), change in human resources will be expected, as well as re-evaluating the paradigms. A managerial skill will be needed to pull people together for the reputation of the company.

\subsection{Environmental Risks}

Employees who are not happy with the organization will manifest their dissatisfaction to the outside world. Customers are bound to experience unwelcoming acts of aggression and bitterness emanating from unhappy employees. Poor customer service will be the order of the day among employees which will end up tarnishing the name of the business. A company is bound to even follow international regulations not only it domestic laws (Darroux \& Xixiang, 2013), even those that impact on the environment. 


\subsection{Health Risks}

Employees who are not entirely happy at work can have health problems including stress. Stress related illnesses will jeopardize wellness efforts in the work place of keeping healthy employees. Stressed and de-motivated employees may cause accidents at work when using machineries and other dangerous tools. Work stress and other psychosocial factors are recognized worldwide as a major challenge to workers' health and the health of organizations. All levels in the organization are be responsible for the safety of risks in the company and help with avoidance of such risks (Tasmin and Salehudin, 2016).

\subsection{Financial Risks}

Employees who are highly motivated will always put their best efforts in their work and help the company to be productive. Production at work will bear more output in which it will be able to generate much needed income. If employees are happy absenteeism's will be reduced thereby saving costs for their organisations. Taylor (2009 \& 2012) agree that financial crisis can be because of economic circumstances, making it extremely difficult for business to operate. This then will extend to difficulties in acquisitions. Again according to Peter and Daniel (2013), Political influence, outside the context of deficit accommodation, can also provide accommodation for specific fiscal policy initiatives.

\section{Importance of Motivation in the Workplace}

Motivation can emanate from with an employee with a passion and desire to work and produce results. This kind of motivation is self-driven by an employee in order to elevate his feelings to accomplish. However, in extrinsic motivation, an external factor such as a reward is used to boost the employee's moral and desire to work. As is a normal case, employees work in exchange for compensation for their hard labour but how far they go depends on how motivated they are. According to Perry and Hondeghem (1999), the individuals desire to perform, and provide services to customers, with the mandate to do good is enough factor to motivate. Performance at work is related to the employees pay of which the employee may not have control of that reward as it is external. Apart from rewards, there are other factors that are external such as promotion at work, security of the job, salary increment that may give meaning to employees motivation. Therefore, for organizations to continue existing and retaining its workforce, they must keep on working on strategies that can help in motivating its employees. Motivated employees have a sense of belonging and loyalty to the organization and always work hard to be associated with the results of their labour. Motivation have effect on employees as individuals to achieve and as well as ability to be innovative because they believe in themselves which will benefit the organization to succeed (Yang Jie, 2010). A motivated worker is easy to be retained hence saving the organization finances of replacing workers, also it encourages workers to always achieve more on daily productions as they are having a sense of security of their work. Management will have time to attend to other important issues because their motivated workforce can build teams that can help with the supervision and production of work.

\section{Conclusion}

Motivation is very much needed for employees in an organisation to be productive, and management or leadership style has an important role to play. Motivation is not always based on financial rewards, but non-financial rewards methods can also be used to derive the best out of employees. Although individuals have their expectations, it is the leadership's responsibility to develop and align with theories that are suitable to bring job satisfaction to their employees. However, there is no single reliable theory to be used, a mixture of them can be utilized. In terms of empowering workforce, employees should be encouraged and given a platform to voice out their concerns on how they can be motivated. Rewards and promotions following performance appraisals maybe used to boost 


\section{Reuben M. Badubi}

Theories of Motivation and Their Application in Organizations: A Risk Analysis

employee's moral as well as feedback. All employees should understand the company's vision and goals and work together towards those. In some organizations, workers perform their duties in an assembly whereby if a certain section of employees is affected it will affect the whole plant. Employees perform their duties diligently if they are inspired and motivated as the results will always be positive with efficient production. Organizations which are results oriented will go all the way to motivate their employees for them to reach their goals. A further qualitative research on motivation strategies and theories is recommended.

\section{References}

- Alavi, H.R., \& Askaripur, M.R. The relationship between self-esteem and job satisfaction of personnel in government organizations. Great Britain: Conwell Press, 2003.

- Anderson, H., Singale, M. \& Svana, V. 2001. Psychology in the work context. Oxford: Oxford University Press, 2001.

- David, A. and Anderzej, A. Organisational Behaviour. 7th ed. London: Pearson, 2010.

- Darroux, C. \& Xixiang Sun. Factors Impacting International Marketing: Configuring Strategies and Incorporating Co-Opetition. Proceedings of the 10th International Conference on Innovation and Management, 2013, December 2-4,1056.

- Dessler, G. Human resource management (11th ed.) Upper Saddle River, NJ: Pearson, Prentice Hall, 2008.

- Golshan, N. M., Kaswuri, A.H., Agashahi, B, Amin, M, \& Ismail, W.K.W. Effects of Motivational Factors on Job Satisfaction: An Empirical Study on Malaysian gen-y administrative and Diplomatic Officers 3rd International Conference on Advanced Management Science IPEDR vol 19.

- Hogan, R. And Hogan, J. Assesing Leadership. A view from the dark side International Journal of Selection and Assesment, 2004, 9(1-2), 40-51.

- Jehanzeb, K., Raseed, M.F., Rasheed, A., \& Aamir, A. Impact of rewards and motivation on job satisfaction in banking sector of Saudi Arabia International Journal of Business and Social Science. 2012,3 (21): 271-278.

- Kumar, N. \& Singh, V., Job satisfaction and its correlates [J]. International Journal of Research in Economics \& Social Sciences, 2011,1 (2): 11-24.

- Levy, A. An examination and baseline report on some aspects of absenteeism in South Africa. The Vanishing Workforce Pretoria: Juta \& co, 2006.

- Naveed, A., Usman, A. \& Bushra, F..Promotion: A Predictor of Job Satisfaction A Study of Glass Industry of Lahore (Pakistan) International Journal of Business and Social Science, 2011,2(16): 301-305.

- Peter, J. and Daniel, J.S. (2016). Evolving Views on Monetary Policy in the thought of Hayek, Friedman and Buchanan Journal article on Review of Australian Economics, 2016,29 (4), 351-370.

- Perry J., \& Wise L. The Motivational Bases of Public Service Public Administration Review, 1999, 50(3):367-373 Crossref

- Robbins, S.P. and Judge, T.A. Organizational behaviour.12th edition New Jersey: Pearson Education, Incorporated, 2007.

- Saari, L.M. \& Judge, T.A. Employee attitudes and job satisfaction. Human Resource Management, 2004,43 (4): 395-407. Crossref

- Saif, K.F., Nawaz, A., Jan, A. \& Khan, M.I. Synthesizing the theories of job-satisfaction across the cultural/attitudinal dimensions. Interdisciplinary Journal of Contemporary Research in Business, 2012,3 (9): 1382-1396.

- Smith, P.J., \& Cronje, G.J. Management principles. A Contemporary South African edition. Kenwyn: Juta \& Itd, 1992.

- Stankkiewicz, M. A. Approach to the issues of leadership in the processes of companies' acquisitions 6th International Conference on Applied Human Factors and Ergonomics (AHFE 2015) and the Affiliated Conferences, AHFE 2015. 


\section{Reuben M. Badubi}

Theories of Motivation and Their Application in Organizations: A Risk Analysis

- Tasmin R., Salehuddin, M.F. The Linkage of Potential Hazards with Safety Impact: A view from Floating Storage Facility in Malaysia Proceedings of the 13th International Conference on Innovation and Management. (II), 2016, November, 28-30, 1033.

- Taylor, J. First Principles: Five Keys to Restoring America's Prosperity. New York: W. W. Norton \& Company Inc., 2012.

- Wagner, J.A. \& Hollenburg, J.R. 2007. Organisational Behaviour. 3rd ed. Upper Saddle: Prentice Hall.

- Yang Jie, Jiang Yanyuan. Analysis of Achievement Motivation of College Student. Peking University Education Review, 2010, 8(1): 63-69

- Van der Merwe, R., \& Miller, S. Measuring absence and labor turnover: A practical guide to recording and control. JHB: Lexicon Publishers, 1998. 